\title{
Disaster nursing knowledge in earthquake response and relief among Nepalese nurses working in government and non-government sector
}

\author{
Pritika Basnet ${ }^{* 1}$, Praneed Songwathana ${ }^{2}$, Wipa Sae-Sia ${ }^{2}$ \\ ${ }^{1}$ Faculty of Nursing, Prince of Songkla University, Thailand \\ ${ }^{2}$ Department of Surgical Nursing, Prince of Songkla University, Thailand
}

Received: May 20, 2016

DOI: $10.5430 /$ jnep.v6n11p111
Accepted: June 20, 2016

Online Published: July 11, 2016

URL: http://dx.doi.org/10.5430/jnep.v6n11p111

\begin{abstract}
Background: Recently, the disasters in Nepal as elsewhere has caused a large number of deaths, injury and left hundreds of thousands of people homeless. It has also alerted all nurses to be prepared with adequate knowledge in order to respond to a disaster event effectively. This descriptive study aimed to describe and compare the level of knowledge in an earthquake disaster among Nepalese nurses working in government and non-government hospitals.

Methods: Three hundred working registered nurses (RNs) were randomly selected from fourteen government and four nongovernmental hospitals located in different parts of Nepal. Nurses' knowledge in earthquake disaster was obtained through self-reported questionnaires. Descriptive and inferential statistics were used for data analysis.

Results: The majority of the RNs worked in government hospitals (63.2\%), more than half (59\%) of the respondents had diploma level of education with the majority $(66.3 \%)$ of them working in a hospital for less than six years. Two thirds (78\%) had never attended disaster training drills and nearly half $(47.7 \%)$ of the RNs determined that they themselves were not ready to face a future disaster. The knowledge of the RNs regarding earthquake disaster was at a moderate level (70.07 \pm 10.01$)$. The lowest score of nurses' knowledge was related to assessment and triage in earthquake disaster response. Nurses working in governmental hospitals have a higher mean score of knowledge than those working in non-governmental hospitals $(P<.05)$.

Conclusion: A disaster nursing training course should be provided for nurses particularly in non-governmental hospitals who had never received disaster training which will improve their knowledge in order to respond to future disasters.
\end{abstract}

Key Words: Disaster nursing, Earthquake, Nurse's knowledge

\section{INTRODUCTION}

\subsection{Introduction of the problem}

The incidence of natural disasters has been rapidly increasing. Asia has been often hit with disasters which comprise of $40.7 \%$ of all natural disasters and $90 \%$ of the total global disaster victims. ${ }^{[1]}$ Out of world's reported natural disasters between 2004 and 2013, 41.2\% or 1,690 incidences occurred in the Asia-Pacific region. ${ }^{[2]}$ Globally, earthquake disasters comprised of $7 \%$ of the total victims from all natural disasters in 2013. [1]

Nepal ranks in the 11th position for earthquakes in the world due to its location near the boundary of the Eurasian and Indian tectonic plates. ${ }^{[3]}$ Recent earthquakes (7.9 and 7.2 Richter scale) in Nepal during April and May 2015 resulted

*Correspondence: Pritika Basnet; Email: basnetkhuse20@gmail.com; Address: Koshi Haraicha Municipality-1, Koshi, Morang, Nepal. 
in a huge number of deaths and injuries. This event killed more than 8,673 people, 21,952 people were injured and it left hundreds of thousands of people homeless with some of the villages entirely flattened to the earth. ${ }^{[4]}$

Various health impacts (physical and psychological) are well known after an earthquake disaster. For instance, the common injuries found after earthquakes are soft tissue injuries (including lacerations and contusions), fractures and crush injuries. ${ }^{[5,6]}$ The most common mental illness after an earthquake disaster is psychological distress, depression, anxiety, cognitive disorder and post-traumatic stress disorder. ${ }^{[7]}$ These impacts imply that there is a need to address these problems starting immediately after the disaster event and alert nurses to take their roles during the disasters.

\subsection{Importance of the problem}

Nurses as the largest group of health care providers need to be competent in order to deal with a disaster. ${ }^{[8,9]}$ International Council for Nurses (ICN) disaster nursing alerts all nurses to be prepared with adequate knowledge in order to respond to disaster events effectively. ${ }^{[10]}$ Lack of knowledge regarding nursing care during response and recovery (creates a perplexing environment where the nurses have to cope with limited resources). The response phase activities of the disaster are usually followed by recovery phase activities which continue for 72 hours after the event. ${ }^{[1,12]}$ Thus, the response and recovery phases of the disaster make the highest demands on nurses working to minimize the impact of disaster on human health. Therefore, it is crucial for nurses to have adequate knowledge to respond effectively and quickly during the response and recovery phase of an earthquake disaster.

The education and trainings for the nurses on disaster are still underdeveloped in Asian countries. ${ }^{[13]}$ In addition, research regarding education and training aspects of disasters has been ranked as a second priority among the top ten research areas in disaster nursing. ${ }^{[14]}$

Limited research has been conducted addressing the nurses' knowledge regarding the earthquake disaster in Nepal. Although previous studies have been conducted after earthquakes in developing countries, most studies explored the disaster preparedness knowledge and essential clinical skills specific to one phase. ${ }^{[15,16]}$ This study will focus on nurses' knowledge regarding an earthquake disaster particularly in the response and recovery phases because the health impacts will be more severe when nurses are not able to deal with these impacts. In addition, it will indicate the implications for the education and actual training needs of nurses regarding earthquake disasters. The findings of this study will be beneficial to nursing practice in terms of enhancing the roles of nurses and capacity building in earthquake disasters.

\subsection{Literature review}

An earthquake is one of the natural disasters that has a high occurrence worldwide leading to physical and psychological health impacts on human health. ${ }^{[5,6]}$ Nurses, as a large workforce around the world, must be prepared for a disaster as it can happen to any person, place or nation. ICN has emphasized that every nurse around the world must be prepared in terms of knowledge, skills and judgment regarding a disaster. ${ }^{[10]}$ To work effectively when an earthquake disaster occurs, nurses must have adequate knowledge related to earthquakes.

Studies have found that nurses are not well prepared to respond to disaster events. ${ }^{[8]}$ In addition, studies have explored the nurses' knowledge specific to one phase (preparedness phase) and a disaster in general. ${ }^{[17,18]}$ A developing country like Nepal, which has been hit by the earthquakes frequently, should have well prepared nurses in order to respond to a disaster effectively.

The conceptual framework of nurses' knowledge in this study was adopted from the concept of disaster nursing derived from the ICN framework. ${ }^{[10]}$ In addition, the knowledge related to earthquake disasters from the literature review $^{[5-7,19-21]}$ was added in the framework. Based on the ICN disaster nursing competencies framework, knowledge on the response and recovery phases is the most important for nurses in the hospital setting. Knowledge in the response phase consists of 1) care of the community, 2) care of individuals and families, 3) psychological care and 4) care of vulnerable populations. Knowledge in the recovery phase consists of long term individual, family and community recovery care.

\subsection{Aim of the study}

This study aims to describe the level of knowledge regarding earthquake disasters in the response and recovery phases among RNs in Nepal and to compare the knowledge scores among RNs working in government and non-government hospitals.

\section{Methods}

\subsection{Research design and sampling procedure}

A descriptive comparative study was used to explore the knowledge regarding earthquake disasters among RNs working in the governmental and non-governmental sectors in Nepal. According to the Nepal Nursing Council, ${ }^{[22]}$ the total population of the RNs in Nepal in 2015 was 33,293. The researcher used the Taro Yamane formula ${ }^{[23]}$ in order to

ISSN 1925-4040 E-ISSN 1925-4059 
calculate the sample size of this study. By using the total population of the RNs $(33,293)$, the total sample was calculated using \pm 5 estimated error. Three hundred and ninety-five RNs were initially approached.

At first, four zones were purposively selected from the list of 14 zones in Nepal on the basis of accessibility to those areas. After that, fourteen government hospitals (two central levels, three regional/zonal levels and 8 district levels) and four non-government hospitals were randomly selected from the four zones resulting in the survey of 17 hospitals. The RNs in each hospital were randomly selected by using the proportion formula in order to reach 395 sample sizes. There were approximately 1,857 RNs working in the 17 different levels of hospitals (1,120 from government hospitals and 737 from nongovernment hospitals). In order to estimate the proportionate sampling and reach the estimated sample size, the following formula ${ }^{[24]}$ was used:

$$
n_{1}=\frac{N_{1}}{N_{\text {Total }}} \times n
$$

$n_{1}=$ Sample from hospitals, $N_{1}=$ Population of hospitals, $N_{\text {Total }}=$ Total population of randomly selected zones and districts $(\mathrm{N}=1,857), n=$ sample (395)

Finally, 238 nurses from government hospitals and 157 from non-government hospitals were approached in this study. The sample distribution is shown in Figure 1. The inclusion criteria in this study were RNs 1) having at least 3 years of diploma level of education in general nursing, 2) currently working in a hospital setting and 3) willing to participate in the study.

\subsection{Tool for data collection}

The instrument used in this study consisted of two main parts: 1) Demographic Data Questionnaire (DDQ) and 2) Nurses Knowledge regarding Earthquake Disaster Questionnaire (NKEDQ). The DDQ collected the data related to age, religion, educational level, disaster training and education, work experience as a registered nurse and previous disaster experience. The 30 items of the NKEDQ used true/false $(\mathrm{T} / \mathrm{F})$ questions to measure knowledge on earthquake disasters and nursing care in the response and recovery phases. The NKEDQ has two main sections: knowledge in the response phase contains $24 \mathrm{~T} / \mathrm{F}$ response type questions and knowledge in the recovery phase contains $6 \mathrm{~T} / \mathrm{F}$ response type questions. Items answered correctly were scored 1 and items answered incorrectly were scored 0 . For the standardization of knowledge scores, the scores were converted into a percentage for interpretation. The four levels of knowledge were categorized as very low (scores < 60\%), low $(60 \%$ $69.99 \%)$, moderate (70\%-79.99\%), and high ( $>80 \%)$.

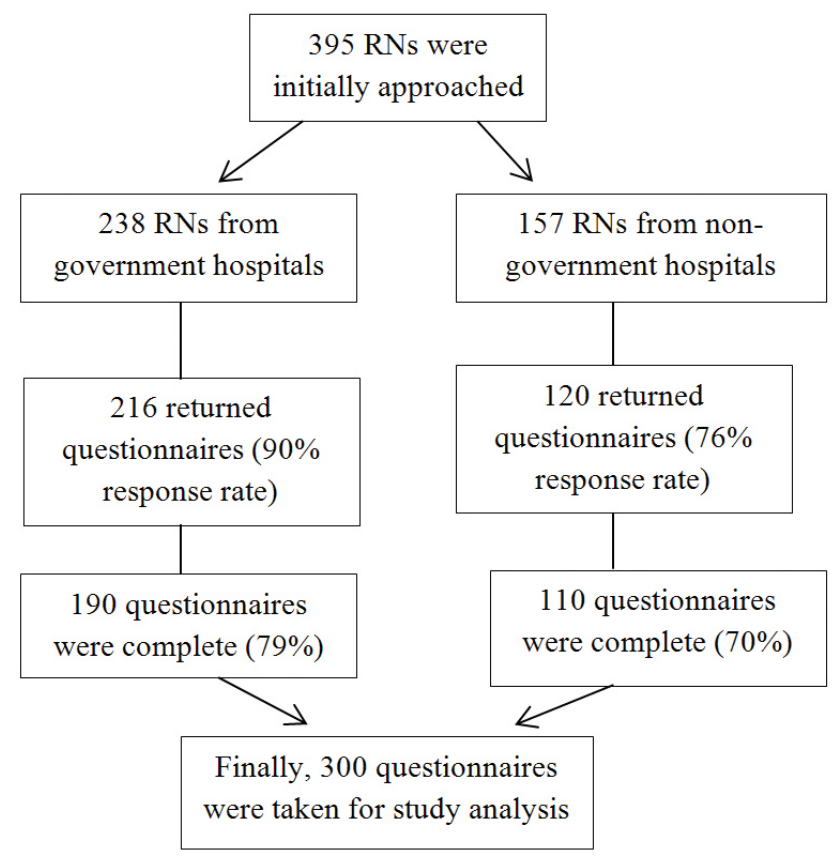

Figure 1. Flow Chart of the Sample Distribution

\section{Validity and reliability of the instrument}

Three experts in emergency and disaster nursing 1) a lecturer from the Faculty of Nursing, Surgical Department, Prince of Songkla University in Thailand, 2) a lecturer from the Faculty of Nursing, Khon Kaen University, Thailand and 3) a nurse administrator working in a general public hospital in Nepal who has experience in disasters and who is currently working for the policy development related to disasters in Nepal, examined the instruments for content validity.

The internal consistency reliability test was conducted using 20 participants who had similar characteristics as the study participants. The NKEDQ was tested for the internal consistency using the Kruder Richardson (KR-20) test with a correlation coefficient of 0.79 . In addition, the average difficulty index (DIF I) and discrimination index (DI) of the NKEDQ was $56.33 \%$ and 0.47 , respectively.

\subsection{Ethical consideration}

All the relevant principles of ethics in research were followed. The study was approved by the Institutional Review Board from the Faculty of Nursing, Prince of Songkla University, Thailand, and the Nepal Health Research Council, Nepal (NHRC). The RNs who agreed voluntarily to participate in the study were briefed about the study and informed about their right to withdraw at any time, for any reason without negative consequences. The researcher maintained anonymity using codes and the information was kept confidential. 


\subsection{Data collection}

After obtaining permission from the hospitals, the questionnaires were distributed to the selected participants via the nursing director allowance. A duration of 2 days to 1 week was given in order to completely fill in and return the questionnaires. Follow up phone calls were made by the researcher with the help of the head nurses in each hospital in the case of RNs who did not return the questionnaire in one week. A total of $395 \mathrm{RNs}$ were approached for participation in the study. 336 questionnaires were returned yielding an $85 \%$ response rate. The data were collected from February, 2016 to April, 2016.

\subsection{Statistical analysis}

Before data analysis, empty and incomplete questionnaires were excluded from the study sample $(\mathrm{n}=36)$. Finally, 300 (76\%) completed questionnaires (190 from government hospitals and 110 from nongovernment hospitals) were used for the study analysis. Firstly, the demographic data was analyzed by using frequencies, percentages, means, and minimum and maximum scores. After that, the data of the knowledge scores were checked for normal distribution and the scores were examined. The data met normal distribution and then the frequencies, percentages, means and standard deviations were used for the data analysis. Furthermore, the comparison of the nurses' knowledge scores between government and nongovernment hospitals were analyzed using independent $t$-test (for comparing total knowledge scores and knowledge in the response phase) and Mann-Whitney $\mathrm{U}$ test (for comparing the knowledge in the recovery phase because the assumptions of the data were not met). The level of significance was set at 0.05 . The mean knowledge scores were converted into a mean percentage for the interpretation of the level of knowledge.

\section{Findings}

\subsection{Demographic characteristics}

As shown in Table 1, the RNs in this study were aged between 20 to 58 years $(27.36 \pm 8.31) .59 \%$ had a nursing diploma, 39.9\% had Bachelor's degree and the rest of the participants at $1.7 \%$ had a Master's degree. Most of the respondents $(66.3 \%)$ had less than 6 years of experience as a registered nurse $(5.94 \pm 7.8) .78 \%$ of the RNs did not have any training and education related to any kind of disasters and only $32 \%$ of RNs had direct experience in disaster care during the last five years. In addition, $47.7 \%$ of them mentioned that they are not ready to face any future disaster. Only $14 \%$ and $12 \%$ of the nurses often read books and searched the internet for information related to disasters, respectively.
Table 1. Demographic characteristics of the participants as categorized by type of hospitals $(\mathrm{N}=300)$

\begin{tabular}{|c|c|c|c|}
\hline $\begin{array}{l}\text { Demographic } \\
\text { Characteristics }\end{array}$ & Total N(\%) & $\begin{array}{l}\text { Government } \\
\text { Hospital } \\
\text { n (\%) }\end{array}$ & $\begin{array}{l}\text { Non-government } \\
\text { Hospitals } \\
\text { n (\%) }\end{array}$ \\
\hline \multicolumn{4}{|l|}{ Age (Years) } \\
\hline$<30$ & 235 (78.3) & $139(73.2)$ & $96(87.3)$ \\
\hline $30-40$ & 38 (12.7) & $29(15.3)$ & $9(8.2)$ \\
\hline $41-50$ & $14(4.7)$ & $10(5.3)$ & $4(3.6)$ \\
\hline$>50$ & $13(4.3)$ & $12(6.1)$ & $1(0.9)$ \\
\hline$\overline{\mathrm{X}} \pm \mathrm{SD}$ & $27.36 \pm 8.31$ & & \\
\hline Range & $20-58$ & & \\
\hline \multicolumn{4}{|l|}{ Nursing education } \\
\hline \multicolumn{4}{|l|}{ Background } \\
\hline Diploma level & $177(59.0)$ & 112 (58.9) & $65(59.1)$ \\
\hline Bachelor level & 118 (39.3) & 74 (38.9) & $44(40.0)$ \\
\hline Master level & $5(1.7)$ & $4(2.2)$ & $1(0.9)$ \\
\hline \multicolumn{4}{|l|}{$\begin{array}{l}\text { Experience in disaster } \\
\text { training or attending } \\
\text { disaster drills }\end{array}$} \\
\hline Yes & $66(22.0)$ & $41(21.6)$ & 85 (77.3) \\
\hline No & $234(78)$ & 149 (78.4) & $25(22.7)$ \\
\hline \multicolumn{4}{|l|}{$\begin{array}{l}\text { Work experience as a } \\
\text { nurse }\end{array}$} \\
\hline$<6$ years & 199 (66.3) & 107 (56.3) & 92 (83.6) \\
\hline $6-10$ years & $52(17.3)$ & 45 (23.7) & $7(6.4)$ \\
\hline$>10$ years & 49 (16.3) & $38(20)$ & $11(10.0)$ \\
\hline$\overline{\mathrm{X}} \pm \mathrm{SD}$ & $5.94 \pm 7.81$ & & \\
\hline Range & $1-38$ & & \\
\hline \multicolumn{4}{|l|}{$\begin{array}{l}\text { Previous disaster } \\
\text { experience }\end{array}$} \\
\hline Yes & 95 (31.7) & $68(35.8)$ & $27(24.7)$ \\
\hline No & 205 (68.3) & $122(64.2)$ & $83(75.3)$ \\
\hline \multicolumn{4}{|l|}{$\begin{array}{l}\text { Disaster } \\
\text { self-preparedness: }\end{array}$} \\
\hline $\begin{array}{l}\text { Read books and } \\
\text { materials }\end{array}$ & $21(7.0)$ & 15 (7.9) & $6(5.4)$ \\
\hline Never & $222(74.0)$ & 149 (78.4) & $73(66.4)$ \\
\hline Sometimes & 43 (14.3) & $23(12.1)$ & $20(18.2)$ \\
\hline $\begin{array}{l}\text { Often } \\
\text { Always }\end{array}$ & $14(4.7)$ & $3(1.6)$ & $11(10.0)$ \\
\hline Search the internet & $41(13.7)$ & $24(12.6)$ & $17(15.5)$ \\
\hline Never & 218 (72.7) & $141(74.2)$ & $77(77.0)$ \\
\hline Sometimes & $36(12.0)$ & $25(13.2)$ & $11(10.0)$ \\
\hline $\begin{array}{l}\text { Often } \\
\text { Always }\end{array}$ & $5(1.7)$ & $0(0.0)$ & $5(4.5)$ \\
\hline
\end{tabular}

\subsection{Level of nurses' knowledge in earthquake disaster}

As illustrated in Table 2, the overall knowledge of the RNs regarding an earthquake disaster was at a moderate level (70.07 $\pm 10.01)$. In each phase, the knowledge in the response phase was at a low level $(66.39 \pm \mathrm{SD}=9.55)$ whereas $\mathrm{RNs}$ ' had a high level of knowledge in the recovery phase (84.84 $\pm 21.42)$. In addition, the knowledge of nurses working in nongovernment hospitals was at a low level whereas, the knowledge of nurses working in government hospitals was at a moderate level.

Furthermore, Table 3 shows the result of the highest and lowest scores of nurses' knowledge related to earthquake disasters. The highest mean percentage score was related to morbidities or injuries caused by earthquake disasters (96.0 
$\pm 20.4)$ followed by resource management $(93.0 \pm 26.1)$ related to assessment and triage in earthquake disaster reand disease outbreak after an earthquake disaster $(93.0 \pm$ sponse (12.0 $\pm 32.9,31.0 \pm 46.2)$, including wound care 26.1). Whereas, the lowest score of nurses' knowledge was $\quad(15.0 \pm 35.8)$.

Table 2. Mean, standard deviation and level of the nurses' knowledge related to earthquake disasters in response and recovery phases categorized by government and non-government hospitals $(\mathrm{N}=300)$

\begin{tabular}{|c|c|c|c|c|c|c|}
\hline \multirow{2}{*}{$\begin{array}{l}\text { Knowledge related to } \\
\text { earthquake disaster }\end{array}$} & \multicolumn{2}{|c|}{ Government Hospital } & \multicolumn{2}{|c|}{ Non-government hospital } & \multicolumn{2}{|l|}{ Total } \\
\hline & $\mathrm{M} \pm S D$ & Level & $\mathrm{M} \pm S D$ & Level & $\mathrm{M} \pm S D$ & Level \\
\hline Total scores & $71.1 \pm 10.27$ & Moderate & $68.3 \pm 9.33$ & Low & $70.07 \pm 10.01$ & Moderate \\
\hline Response phase & $68.25 \pm 9.29$ & Low & $68.75 \pm 9.75$ & Low & $66.39 \pm 9.5$ & Low \\
\hline Recovery phase & $85.83 \pm 23.00$ & high & $83.16 \pm 18.17$ & High & $84.83 \pm 21.33$ & High \\
\hline
\end{tabular}

Note. $\mathrm{M}=$ Mean Percentage, $S D=$ Standard deviation

Table 3. Mean, standard deviation and level of the top three highest and top three lowest knowledge scores categorized by items of knowledge related to earthquake disaster $(\mathrm{N}=$ 300)

\begin{tabular}{|c|c|c|c|}
\hline Items & $\mathbf{M} \pm S D$ & Level & $\begin{array}{l}\text { Disaster } \\
\text { Phase }\end{array}$ \\
\hline \multicolumn{4}{|c|}{ Top three highest scores of knowledge } \\
\hline $\begin{array}{l}\text { Morbidities or injuries caused } \\
\text { by earthquake disaster }\end{array}$ & $96.0 \pm 20.4$ & High & Response \\
\hline Resource management & $93.0 \pm 26.1$ & High & Response \\
\hline $\begin{array}{l}\text { Possible interventions to } \\
\text { control outbreak of infectious } \\
\text { disease }\end{array}$ & $93.0 \pm 26.1$ & High & Recovery \\
\hline \multicolumn{4}{|c|}{ Top three lowest scores of knowledge } \\
\hline $\begin{array}{l}\text { Identify the purpose of triage } \\
\text { in earthquake disaster } \\
\text { response. }\end{array}$ & $12.0 \pm 32.9$ & Very low & Response \\
\hline Wound assessment and care & $15.0 \pm 35.8$ & Very low & Response \\
\hline $\begin{array}{l}\text { Triage assessment and triage } \\
\text { in earthquake disaster } \\
\text { response }\end{array}$ & $31.0 \pm 46.2$ & Very low & Response \\
\hline
\end{tabular}

Note. $\mathrm{M}=$ Mean Percentage, $S D=$ Standard Deviation

Table 4. Comparison of knowledge scores between nurses working in government and non-government hospitals

\begin{tabular}{|c|c|c|c|c|}
\hline \multirow[b]{2}{*}{$\begin{array}{l}\text { Knowledge related } \\
\text { to earthquake } \\
\text { disaster }\end{array}$} & \multicolumn{2}{|l|}{ Studied group } & \multirow[b]{2}{*}{$t$} & \multirow[b]{2}{*}{$\boldsymbol{P}$} \\
\hline & $\begin{array}{l}\text { Government } \\
\text { hospitals } \\
\overline{\mathrm{x}} \pm S D\end{array}$ & $\begin{array}{l}\text { Non-government } \\
\text { hospitals } \\
\overline{\mathrm{x}} \pm S D\end{array}$ & & \\
\hline Total score & $21.03 \pm 3.08$ & $20.49 \pm 2.80$ & 2.35 & $<.05$ \\
\hline \multirow[t]{2}{*}{ Response phase } & $16.18 \pm 2.23$ & $16.50 \pm 2.34$ & 2.51 & $<.05$ \\
\hline & Median \pm IQR & Median \pm IQR & z-value & \\
\hline Recovery phase & $6.00 \pm 1.00$ & $5.00 \pm 2.00$ & $-2.335^{*}$ & $<.05$ \\
\hline
\end{tabular}

* Mann Whitney U test

\subsection{Comparison of nurses' knowledge score between nurses working in government and non-government hospitals}

There was a statistically significant difference in knowledge between the nurses working at government and nongovernment hospitals. RNs who worked at government hos- pitals had a higher knowledge score than those who worked in non-government hospitals $(P<.05)$ (see Table 4$)$.

\section{Discussion}

This study had two major findings related to knowledge on earthquake disasters. The first main finding was that the nurses' knowledge on earthquake disasters was at a moderate level. In regards to the knowledge, the knowledge in the response phase was at a low level whereas, that in the recovery phase was at a high level. There were four possible explanations related to a nurse's educational level, the age of the participant, training and education, and disaster experience.

The educational level of the nurses plays a vital role in enhancing the knowledge of the nurses by upgrading the skills to seek information, for example, read books and search the internet by themselves related to earthquake disaster. More than half of the RNs (59\%) in this study were educated at diploma level, therefore their existing knowledge on disaster nursing related to earthquakes may be limited. This is similar to a previous study by Chan in $2009^{[25]}$ who found that Hong Kong nurses who had a baccalaureate, master or doctoral level of education showed a higher level of knowledge than the nurses at a diploma level in a clinical management system. In addition, insufficiency in skills to seek information as a part of education level might influence the nurses' level of knowledge. Since the preparedness to participate in disaster activities plays a greater role in enhancing the knowledge of nurses on disasters. ${ }^{[26]}$ However, only $14 \%$ and $12 \%$ of RNs in this study often read books and surfed the internet to gain knowledge related to disasters in order to prepare themselves for the disaster. So, the necessary skills to seek information related to a disaster may be required which is similar to the previous studies in terms of insufficient or moderate level of knowledge related to preparedness of different types of disaster. ${ }^{[17,27,28]}$

In addition, the age of the participants also influences the 
knowledge of the nurses. The majority of the nurses (78\%) in this study were aged below 30 years. This is similar to a previous study which showed that nurses who were young (26-30 years) had lower levels of knowledge than older adults (31-40 years) in clinical management systems. ${ }^{[25]}$ This finding could be linked with the higher skills through years of experience among older nurses.

The level of knowledge was low particularly in the response phase. The majority of nurses incorrectly answered questions related to the triage and wound care item (see Table 3 ) indicating a low level of knowledge regarding triage and wound care in the response phase. This finding of the study is in accordance with the previous study ${ }^{[29]}$ which found a low level of triage knowledge among emergency nurses and the level of a nurse's education might affect the nurse's role in responding to an emergency disaster. Whereas, Hermawati ${ }^{[30]}$ found a moderately high level of perceived knowledge among nurses in triage and wound care. This difference may be due to two reasons. Firstly, the previous study had recruited the samples from only one central hospital whereas this study included nurses from central to district levels of hospitals. Secondly, the majority of the nurses $(86 \%)$ in the previous study had attended training and education related to disasters whereas the majority of nurses $(78 \%)$ in this study did not have any training and education related to disasters.

In terms of knowledge related to the recovery phase, it was found at a high level. This finding indicates that nurses were more involved and aware of the disaster relief activities and the importance of such activities. This is partly because many nurses may themselves have been the victim of a disaster and they were able to participate in the post disaster phase rather than the response phase. In addition, comparatively more nurses would be dispatched for patient care as found in the previous study where more than $55 \%$ of the Japanese nurses were dispatched in the post-disaster phase so they had less experience in the response phase care. ${ }^{[31]}$

The third reason for the explanation of overall knowledge at a moderate level is related to a nurse's experience in disaster and attending the disaster training. The experience in disaster training and having a direct experience of a disaster may also help to upgrade the knowledge and confidence of the nurses to respond to disasters. ${ }^{[18,30]}$ Since the experience and training can help nurses gain insight and absorb information from others and learn from any mistakes, and repeated actions in similar situations may increase knowledge. However, seventy-eight percent of the respondents in this study did not have experiences in disaster training and had no direct experience in disaster care (63.2\%). Similar evidence was also shown in a previous study, that more than half of the nurses in Japan who took part in humanitarian aid and disaster response did not have any disaster medical training experience ${ }^{[31]}$ and this might have affected the level of knowledge. Thus, a low level of knowledge in a response phase was found.

The second main finding of this study was that nurses working in government hospitals had higher knowledge scores than those working in non-government hospitals. This finding can be clarified with some supporting ideas and evidence. Firstly, Nepal like other countries has a National Disaster Relief Act (NDRA) which was introduced in 1982 in order to formulate a well-structured disaster management policy. However, the duties and responsibilities of all disaster management are centered in the government of Nepal. ${ }^{[32]}$ So, all the training at the national level is centered on the government level of hospital staff. Another reason may be the experience of nurses in previous disaster care; nurses working in government hospitals had more experience in previous disaster care than nurses working in non-government hospitals. Previous studies also found that nurses who had previous experience in disaster care had higher levels of knowledge in disaster preparedness. ${ }^{[33]}$ In addition, work experience also plays a great role in boosting the knowledge of the nurses as mentioned above. ${ }^{[17]}$

In contrast to previous studies on nurses' disaster knowledge in Jordan and Israel, it was found that government hospital nurses had lower levels of knowledge than nursing staff in military and university hospitals. ${ }^{[17,26]}$ The reason behind the contrast in findings may be from the frequent training required by health care policy targeted at military hospitals. This might be different from the Nepalese context which targets government hospitals. In addition, nurses in those countries that are exposed to war and terrorists might have access to more resources and experience related to disaster care which can help nurses to improve their level of knowledge.

Preparing nurses through disaster training and education has become an international concern due to frequently occurring disasters throughout the world. When a disaster happens, every nurse is required to and has responsibilities to respond to and face the disaster regardless of the department they work in, the type of hospital and the level of hospital. Many international studies have recommended training and education related to disasters in order to increase the level of disaster awareness among nurses and prepare them to respond disaster events effectively. ${ }^{[17,26,28,31]}$ Nearly half of the respondents in this study did not perceive that they were prepared to respond to a future disaster. Nepal as well as other developing countries has obtained disaster training with the assistance from both national and international organi- 
zations. ${ }^{[34]}$ However, this study shows that the training is still insufficient for Nepalese nurses especially those who were working in non-government hospitals. So, ongoing training should be provided to every level of nurses working in different hospitals.

\section{LIMITATION OF THE STUDY}

The findings may not be generalized to all registered nurses in Nepal due to some limitations. The study participants involved were only working registered nurses in hospitals without including nurse educators and public health nurses. In addition, the findings of this study were specific to government and some non-government hospitals. The knowledge questionnaire was only focused on disaster nursing in the response and recovery phases.

\section{CONCLUSION AND RECOMMENDATIONS}

The overall knowledge of the nurses in this study was at a moderate level. Nurses working in government hospitals had a higher knowledge score than nurses in non-government hospitals. In addition, the majority of the nurses had never received disaster training and education related to earthquakes. Nepal urgently needs to provide disaster nursing training with the support of nurse leaders and the government as well as integrate content specific to earthquakes in future disaster nursing education at the diploma level. The findings could serve as evidence for health policy makers or stakeholders in the hospital to prepare and raise the awareness of nurses to respond to upcoming disasters. Hospitals must establish a disaster response plan and initiate in- service education, disaster training, mock drill exercises particularly in triage and wound care and facilitate nurses to search resources related to disaster nursing care for self-directed learning (for example-providing computers and access to the internet, providing books and articles related to disasters). Further study is needed to develop a knowledge package or program to improve nurses' knowledge particularly in the response phase and to test the effect of the program on clinical skills in disaster care.

\section{ACKNOWLEDGEMENTS}

The authors would like to thank the medical and nursing directors of the seventeen hospitals for facilitating the data collection and all the nurses who participated in this study who provided their valuable time in order to fill in the questionnaires of this study. In addition, the authors would like to give their sincerest thanks to the Graduate School and Research Center for Caring and Healing System for People with Trauma, Emergency and Disaster, Prince of Songkla University, Thailand for the partial funding support of this study and publication.

\section{CONFlicts OF InTEREST Disclosure}

The authors declare that they have no conflicts of interest.

\section{REFERENCES}

[1] Guha-Sapir, Hoyois P, Below R. Annual Disaster Statistical Review 2013- The numbers and trends. Brussels, Belgium: Centre for Research on the Epidemiology of Disasters (CRED). 2014. Available from: http://cred.be/sites/default/files/ADSR _2013.pdf (31 September 2015 date last accessed).

[2] United-Nation. Statistical Yearbook for Asia and the Pacific. 2014. Available from: http://www . unescap.org/sites/default/fi les/ESCAP-SYB2014.pdf (25 August 2015 date last accessed).

[3] Koirala PK. Disaster management Institution and System in Nepal. Kathmandu: Ministry from Home affairs, 2014. Available from: http://reliefweb.int/report/nepal/disaster-man agement-institution-and-system-nepal (1 May 2016 date last accessed).

[4] United Nation High Commissioner for Refugees (UNHCR). Nepal: 2015 Earthquakes and Aftershocks, People Killed/Injured by District (as of 26 May 2015). 2015. Available from: http://reliefwe b.int/map/nepal/nepal-2015-earthquakes-and-aftersh ocks-people-killed-injured-district-26-may-2015 (14 May 2016 date last accessed).

[5] Doocy S, Daniels A, Packer C, et al. The Human Impact of Earthquakes: a Historical Review of Events 1980-2009 and Systematic Literature Review. PLOS Currents Disasters. 2013, 5. PMid:
3644288. http://dx.doi.org/10.1371/currents.dis.67bd $14 \mathrm{fe} 457 \mathrm{f} 1 \mathrm{db} 0 \mathrm{~b} 5433 \mathrm{a} 8 \mathrm{ee} 20 \mathrm{fb} 833$

[6] Lu-Ping Z, Rodriguez-Llanes JM, Qi W, et al. Multiple injuries after earthquakes: a retrospective analysis on 1,871 injured patients from the 2008 Wenchuan earthquake. Critical Care. 2012;16(3): R87. PMid:3580632. http://dx.doi.org/10.1186/cc11349

[7] Tachibana A, Kitamura H, Shindo M, et al. Psychological distress in an earthquake-devastated area with pre-existing high rate of suicide. Psychiatry Research. 2014; 219(2): 336-340. http: //dx.doi.org/10.1016/j.psychres.2014.01.028

[8] Yang YN, Xiao LD, Cheng HY, et al. Chinese nurses' experience in the Wenchuan earthquake relief. International Nursing Review. 2010; 57(2): 217-223. http://dx.doi.org/10.1111/j.1466-7 $657.2009 .00795 . x$

[9] Wee FC. (P2-56) Nurses' Knowledge, Skills and Perception Towards Disaster Response and Emergency Preparedness. Prehospital and Disaster Medicine. 2011; 26(SupplementS1): s154. http: //dx.doi.org/10.1017/S1049023X11005000

[10] International Council for Nurses (ICN). ICN Framework of Disaster Nursing Competencies. Geneva, Switzerland: World Health Organization, 2009. Available from: http://www.icn.ch/ima ges/stories/documents/networks/DisasterPreparedn essNetwork/Disaster_Nursing_Competencies_lite.pdf (11October 2015 date last accessed). 
[11] Baird M. The recovery phase of emergency management. Prepared for the Intermodal Freight Transportation Institute, University of Memphis, Tennessee. 2010. Available from: http://www . vander bilt.edu/vector/research/recoveryphase.pdf (15 August 2015 date last accessed)

[12] Veenema TG. Disaster Nursing and Emergency Preparedness: For Chemical, Biological, and Radiological Terrorism and Other Hazards: Springer Publishing Company; 2007.

[13] Sasaki I, Ohara M, Higashiura H, et al. The Current Situation of Disasters and Disaster Nursing Education in Asian Universities. Japan: Japanese Red Cross College of Nursing, 2014. Available from: http://www.jsdn.gr.jp/english/pdf/The\%20Prese nt $\% 20$ Situation $\% 20$ of $\% 20$ Disaster $\% 20$ Nursing $\% 20$ Educati on $\% 20$ at $\% 20$ Nursing $\% 20$ Colleges $\% 20$ and $\% 20$ Universities $\%$ 20 in $\% 20$ Asian $\% 20$ Region\%20 (JSDN) . pdf (11October 2015 date last accessed)

[14] Ranse J, Hutton A, Jeeawody B, et al. What are the research needs for the field of disaster nursing? An international delphi study. Prehospital and Disaster Medicine. 2014; 29(5): 448-454 http://dx.doi.org/10.1017/S1049023X14000946

[15] Ibrahim FAA. Nurses Knowledge, Attitudes, Practices and Familiarity Regarding Disaster and Emergency Preparedness - Saudi Arabia. American Journal of Nursing Science. 2014; 3(2): 18-25. http://dx.doi.org/10.11648/j . ajns. 20140302.12

[16] Baack S, Alfred D. Nurses' Preparedness and Perceived Competence in Managing Disasters. Journal of Nursing Scholarship. 2013; 45(3): 281-287. http://dx.doi.org/10.1111/jnu. 12029

[17] Al Khalaileh MA, Bond E, Alasad JA. Jordanian nurses' perceptions of their preparedness for disaster management. International Emergency Nursing. 2012; 20(1): 14-23. http://dx.doi.org/10.10 16/j.ienj.2011.01.001

[18] Chapman K, Arbon P. Are nurses ready?: Disaster preparedness in the acute setting. Australasian Emergency Nursing Journal. 2008; 11(3): 135-144. http://dx.doi.org/10.1016/j.aenj . 2008.04.002

[19] Ali, Mir AA, Jabeen R, Ahmad M, et al. Morbidity pattern and impact of rehabilitative services in Earth quake victims of kashmir, India. International Journal of Health Sciences. 2010; 4(1): 59-67. PMid: 3068802 Available from: http://www.ncbi.nlm.nih.g ov/pmc/articles/PMC3068802/

[20] Aliakbari F, Hammad K, Bahrami M, et al. Ethical and legal challenges associated with disaster nursing. Nursing Ethics. 2015; 22(4): 493-503. http://dx.doi .org/10.1177/0969733014534877

[21] Li, Zheng J. Efficient post-disaster patient transportation and transfer: experiences and lessons learned in emergency medical rescue in Aceh after the 2004 Asian tsunami. Military Medicine. 2014; 179(8): 913-919. http://dx.doi.org/10.7205/MILMED-D-13-00525
[22] Nepal Nursing Council. Registration status of Nurses. 2015. Available from: http: //www.nnc.org.np/ (10 July 2015 date last accessed).

[23] Polit DF, Beck CT. Nursing Research: Generating and Assessing Evidence for Nursing Practice. 9 th ed. Philadelphia: Lippincott Williams \& Wilkins.; 2012.

[24] Stat trek. com. Sample Size: Stratified Random Samples. 2016. Available from: http://stattrek.com/sample-size/stratified - sample .aspx (6 August 2015 date last accessed).

[25] Chan MF. Factors affecting knowledge, attitudes, and skills levels for nursing staff toward the clinical management system in Hong Kong. Computers, informatics, nursing: CIN. 2009; 27(1): 57-65. http://dx.doi.org/10.1097/NCN.0b013e31818dd3b0

[26] Al Thobaity A, Plummer V, Innes K, et al. Perceptions of knowledge of disaster management among military and civilian nurses in Saudi Arabia. Australasian Emergency Nursing Journal. 2015; 18(3): 156-164. http://dx.doi.org/10.1016/j.aenj . 2015.03.001

[27] Husna C. Perceived clinical skills for tsunami care and its related factors among nurses in Banda Aceh, Indonesia. (Master's thesis) Prince of Songkla University, Thailand; 2010.

[28] Usher Mills J, West C, Casella E, et al. Cross-sectional survey of the disaster preparedness of nurses across the Asia-Pacific region. Nursing \& Health Sciences. 2015; 17(4): 434-443. http: //dx.doi.org/10.1111/nhs. 12211

[29] Fathoni M, Sangchan H, Songwathana P. Relationships between Triage Knowledge, Training, Working Experiences and Triage Skills among Emergency Nurses in East Java, Indonesia. Nurse Media Journal of Nursing. 2013; 3(1): 511-525. http://dx. doi .org/10.14 $710 /$ nmjn.v3i1. 4466

[30] Hermawati D. Nurses' Preparedness of Knowledge and Skills in Caring for Patients Attacked by Tsunami in Indonesia and Its Relating Factors. (Master's thesis)Prince of Songkla University, Thailand; 2010.

[31] Noguchi N, Inoue S, Shimanoe C, et al. Factors Associated with Nursing Activities in Humanitarian Aid and Disaster Relief. PLoS ONE. 2016; 11(3): e0151170. http://dx.doi.org/10.1371/j ournal. pone. 0151170

[32] Disaster Management System Nepal. Legal System of Disaster Management in Nepal. 2004. Available from: http://dpnetnepal.t ripod.com/id15.html (5 May 2016 date last accessed)

[33] Hammad KS, Arbon P, Gebbie K, et al. Nursing in the emergency department (ED) during a disaster: a review of the current literature. Australasian Emergency Nursing Journal : AENJ. 2012; 15(4): 235244. http://dx.doi .org/10.1016/j.aenj . 2012.10.005

[34] Tokyo Development Learning Center. Preparing for disaster: Report on second delivery of disaster nursing training course.2012. Available from: http://www.jointokyo.0rg/en/news/story/dn_2012 (5 May 2016 date last accessed). 